\title{
Human Resource Management (HRM), Economic Crisis (EC) and Business Life Cycle (BLC): A Literature Review and Discussion
}

\author{
Fotios V. Mitsakis \\ Dept. of Human Resource Management, University of Strathclyde \\ Glasgow G1 1XU, Scotland \\ E-mails: fotis.mitsakis@strath.ac.uk / fotisathens@hotmail.com
}

Doi:10.5296/ijhrs.v4i1.5303

URL: http://dx.doi.org/10.5296/ijhrs.v4i1.5303

\begin{abstract}
Today's turbulent business environments require from firms to continuously re-shape their HR practices and strategies in order to sustain competitiveness within the market. Among numerous factors affecting a firm's viability and effectiveness, the recent EC, along with firm's BLC, will also present distinctive opportunities and obstacles that will impact upon business's units and operations. Identifying a firm's life stage will help organizations to acknowledge their competencies and constricts so to successufully manage future challenges. The present paper examines the different BLC stages, their obstacles and the competitve strategies which organizations can implement on each phase. Based on Hoy's (2006) BLC model, the stages are analyzed in accordance with business' HR implementations and strategies. Additional reference is concentrated on the organizational life cycle in the banking industry. Therefore, the paper presents an extensive overview of the relevant literature on business life cycles models, followed by and analysis of a specific BLC model suggested by Hoy (2006).
\end{abstract}

Keywords: Human Resources (HR), Economic Crisis, Business Life Cycle, Banking Industry.

\section{Introduction}

For the majority of firms, the current financial crisis resulted in changes within their operations in general and HR policies in particular. The EC, characterized by increased volatility and uncertainty, has also complicated the implementation of any organizational HR practice (Susaeta et al., 2013). In this regard, Conner \& Ulrich (1996) associated HRM's 
development with business's evolution and economic progress, by suggesting that HR department's roles and duties should successfully address the changes occur within the business economic cycle. That can also be deduced through a wide variety of BLC models, all identifying organizations' maneuvers (moving from one stage to another) after facing major crisis events (Phelps et al., 2007). Linking HRM with business strategy presupposes HR's fit with the organizational life cycle stages. Accordingly, Schein (2010) argued that HRD must be aligned with each stage of an organization's life cycle, while Baird \& Meshoulam (1992) proposed five developmental stages within which HR's needs differentiate, as presented below. Obviously, BLC's phases can affect the way organizations manage and develop their human capital. To that end, HR professionals need to carefully understand each of the BLC stages, so being able to better plan their future HR interventions.

\begin{tabular}{lll}
\multicolumn{1}{c}{ LIFE CYCLE STAGE, CULTURESTRATEGY AND IMPLICATIONS } \\
FOR HRD ACTIVIrIES
\end{tabular}

\section{ORGANISATIONAL STAGES AND HUMAN RESOURCE} MANAGEMENT NEEDS

\begin{tabular}{|c|c|}
\hline Organisational stage & Human resource management needs \\
\hline \multicolumn{2}{|l|}{ Stage I: START UP } \\
\hline $\begin{array}{l}\text { - Entrepreneurship, founder } \\
\text { management, informality, } \\
\text { limited products and markets }\end{array}$ & $\begin{array}{l}\text { - Recruiting to find key people, } \\
\text { basic compensation and } \\
\text { administrative systems }\end{array}$ \\
\hline \multicolumn{2}{|l|}{ Stage II: GROWTH } \\
\hline $\begin{array}{l}\text { - Dynamic growth, technical specia- } \\
\text { lisation, expanded product lines } \\
\text { and markets, added formality } \\
\text { and structure, professional mana- } \\
\text { gement introduced }\end{array}$ & $\begin{array}{l}\text { - Advanced recruiting capability, } \\
\text { training and socialisation } \\
\text { programmes to adapt new } \\
\text { employees to the organisation }\end{array}$ \\
\hline
\end{tabular}

Stage III: CONTROL

- Competition for resources, pres- - Cost control of HR programmes, sure to increase productivity, controlled investment in business controlled investments. related skills. Computer used to analyse costs.

\section{Stage IV: INTEGRATION}

- Diversification, decentralisation, - Effective integration mechanisms product groups or divisions, between the various HR compoproject management. Focus on nents, planning and organisation co-ordination and integration. development capability.

Stage V: FLEXIBILITY

- Adaptability, collaborative team- - Highly developed monitoring work, team action, full integration and scanning capability, flexiacross functional areas, multiple bility to adjust to market and products and markets.

\section{Organizations and Business Life Cycle (BLC)}

An organization's BLC is one of the most common and useful tools while formulating and implementing business strategies. Each firm has its own life cycle with distinctive characteristics in each stage; in that event, that makes it too difficult to calculate an organization's life (Vaxevanidou \& Reklitis, 2008: 45-47). BLC's stages are highly associated 


\section{Mll Macrothink}

with organizational HR practices, since each stage can impel and form them. In this regard, both Kozlowski et al. (1993) and Jackson and Schuler (1995) suggested that if a good fit between HR and BLC achieved, it would result to enhanced organizational effectiveness and competitiveness. Additionally, Kochan \& Chalykoff (1986) argued that continuous economic pressures affect organizations' HR policies, practices and innovations every time they advance to another stage. More precisely, the banking industry, around the globe, has experienced high levels of growth and competition in recent years, resulting in increased organizational complexity, making BLC's understanding more imperative than ever (Metzger, 1989: 390). Nowadays, within the literature agenda, there is a debate whether the recent economic crisis strengthens or weakens HR's strategic role all over an organization's life cycle.

Matching HRM with BLC triggered the interest of many researchers, with many relevant studies focusing on the relationship between HR and BLC. Among the first scholars suggesting that every business has its own life, and accordingly developed their model, was Lippitt \& Schmidt (1967). Either from an "organizational goals" perspective or an "organizational structure" or leadership dimension, scholars proposed their respective life-cycle model, and presented its distinctive characteristics, as summarized with the following figure.

Life-cycle models and the distinguishable characteristics

\begin{tabular}{|c|c|c|}
\hline Scholars & Characteristics & Life-cycle model \\
\hline $\begin{array}{l}\text { Lippitt and Schmidt } \\
(1967)^{*}\end{array}$ & $\begin{array}{l}\text { Age, management focus, different interest groups' priorities, crises and presence } \\
\text { of confrontation, structure, management formalization }\end{array}$ & $\begin{array}{l}\text { Birth, adolescence, } \\
\text { maturity }\end{array}$ \\
\hline Churchill and Lewis (1983) & Age, size, dispersion, complexity & $\begin{array}{l}\text { Existence, survival, success, take-off and } \\
\text { resource maturity }\end{array}$ \\
\hline $\begin{array}{l}\text { Quinn and Cameron } \\
(1983)^{*}\end{array}$ & Age, size, efficiency, structure, formalization, centralization, leadership, culture & $\begin{array}{l}\text { Entrepreneurial, collectivity, formalization, } \\
\text { elaboration of structure }\end{array}$ \\
\hline Schein $(1985)^{*}$ & $\begin{array}{l}\text { Culture function, management generation, complexity, size, management style, } \\
\text { top management composition }\end{array}$ & $\begin{array}{l}\text { Birth or early growth, middle life, organizational } \\
\text { maturity }\end{array}$ \\
\hline Smith et al. $(1985)^{*}$ & $\begin{array}{l}\text { Age, size (sales), size (staff), growth rate, top managers' priorities, Structural } \\
\text { form, remuneration system, centralization, top managers' interaction }\end{array}$ & Inception, high growth, maturity \\
\hline Flamholtz* (1986) & $\begin{array}{l}\text { Age, size, growth rate, critical development objectives, organization, formalization } \\
\text { of planning, control, budgeting, operational and management systems, leadership, } \\
\text { decision-making }\end{array}$ & $\begin{array}{l}\text { New venture, expansion, professionalization, } \\
\text { consolidation, diversification, integration, decline }\end{array}$ \\
\hline Scott and Bruce $(1987)^{*}$ & $\begin{array}{l}\text { Age, size, growth rate, industry development stage, key challenges, Structural } \\
\text { form, control system formalization, top management style }\end{array}$ & Inception, survival, growth, expansion, maturity \\
\hline Hanks et al. (1993)* & $\begin{array}{l}\text { Age, size, growth rate, structure, formalization and centralization degree, } \\
\text { specialization }\end{array}$ & Creation, commercialization, growth, maturity \\
\hline Adizes (1999)* & $\begin{array}{l}\text { Age, size, normal and transition challenges, structural form, formalization of } \\
\text { policies and procedures, leadership qualities needed, diversity, complexity }\end{array}$ & $\begin{array}{l}\text { Courtship, infancy, go-go, adolescence, prime, } \\
\text { stability, aristocracy, salem city, bureaucracy, } \\
\text { death }\end{array}$ \\
\hline Allen (1999) & Age, size, focus, diversity, and complexity & $\begin{array}{l}\text { Pre-start-up, start-up, growth, maturity, rebirth or } \\
\text { decline }\end{array}$ \\
\hline $\begin{array}{l}\text { Smallbone and Wyer } \\
(2000)\end{array}$ & $\begin{array}{l}\text { Age, size, growth rate, organization structure, information processes, control, plan, } \\
\text { strategy }\end{array}$ & $\begin{array}{l}\text { Start-up, survival/development, growth, maturity, } \\
\text { decline }\end{array}$ \\
\hline Lester et al. (2003)* & Age, size, power, information processing, type of organizational structure & Existence, survival, success, revival, decline \\
\hline Hoy $(2006)^{*}$ & Age, size, founding leader's personality & Birth, growth, maturity, decline/renewal, death \\
\hline
\end{tabular}

In brief, BLC ranges between three to ten stages. What is also obvious is that all scholars indicate the age and the size of an organization as the two main characteristics of their model. These two characteristics differentiate as the organization passes through the life-cycle stages. While, each organization sets its goals and objectives, it faces various difficulties in order to meet them, to develop and compete every time it changes and moves to another stage of its 
life cycle (Carter \& Jones-Evans, 2012). Every stage encounters different challenges and problems for the organization, while the stage in which a firm operates also affects its ability to finance its operations and business. To that end, the way in which firms address and manage these problems will affect their viability and the development of their organizational behavior over their life (Milliman et al., 1991; Smith et al., 1985). Furthermore, the advent of the recent global financial crisis also put pressures to firms. Gao \& Alas (2010) research, on 156 Chinese firms, clearly demonstrated the above assertion, by highlighting that half of the crises identified and associated with organizations were related to economy, followed by other types of crises in smaller percentages. Based on Hoy's (2006) model, organizational life cycles consist of the following stages: Birth, Growth, Maturity, and Decline (Renewal or Death), as illustrated below.

\section{Life-Cycle Model}

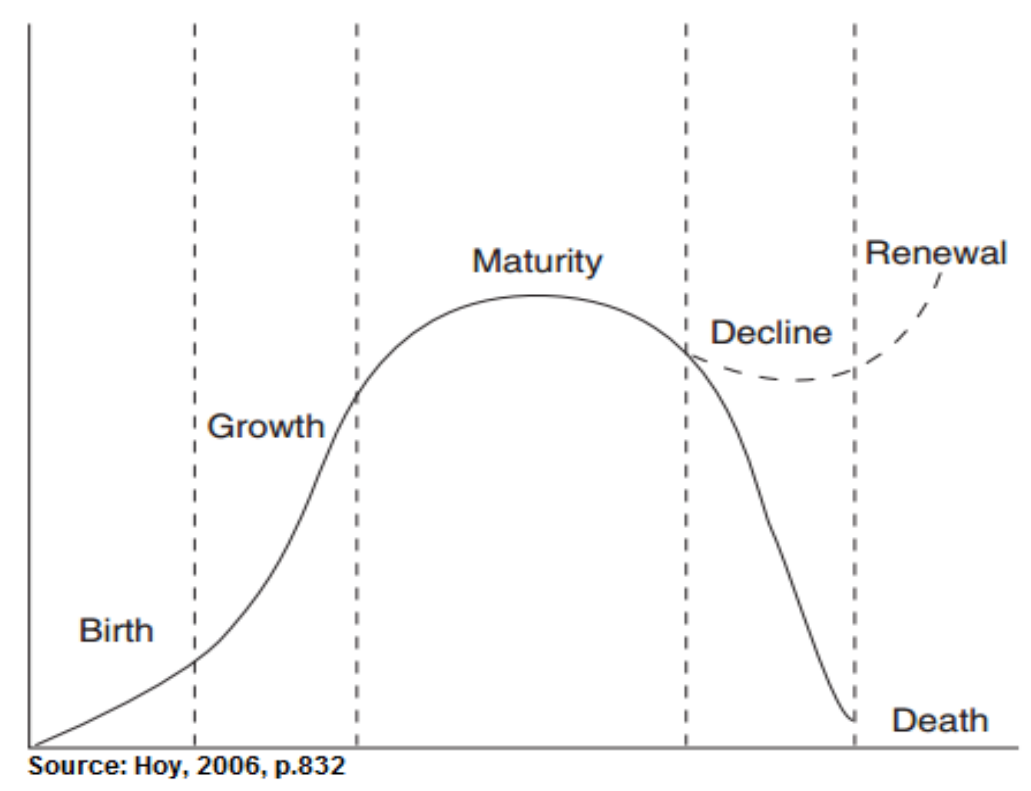

Within each stage of its life cycle, organizations will employ the most appropriate strategy in order to gain or to sustain competitive advantage over its competitors. Based on Porter's (1985) model of competitive advantage, there are three strategies available for businesses: 1) cost-reduction, 2) quality enhancement, and 3) innovation. Organizations usually apply one of these strategies at a time; however, the simultaneous use of more than one strategy is possible. Consequently, adapting the expedient competitive strategy within each stage, it will form HR practices as well. Thereafter, the latter will be highly liked both with BLC stages and competitive strategy, will be influenced by them, and they will, accordingly and continuously, be redefined.

\subsection{HR and the Economic Crisis}

Generally, the literature dispute resulted in three strands of argument regarding HR's current state. The first suggests that the EC will have a cataclysmic effect on HR or even on the viability of long prevalent employment models (Roche \& Teague, 2012: 3). A study 
among HR executives in leading global companies concluded that numbers working in HR would be cut disproportionately compared with other support functions, while "transactional" HR processes would be increasingly relocated to low-cost countries (Pitcher, 2008). Other authors further warn of a possible long-term fall in numbers employed in the HR function, while, contrariwise, others believe that HR's focus would make a shift towards adapting a more strategic direction, and eventually it will become more mature and resilient, by engaging more in proactive actions rather than delivering routine transactional $\mathrm{HR}$ administration (Roche et al., 2011; Phillips, 2008). A second strand suggests that HR's status, cachet and endowment will be strengthened by the recent EC for those firms seeing the crisis as an opportunity by developing strategically mature and resilient HR practices, following a "high-commitment" HR model (Roche et al., 2011). In this regard, Ulrich (as reported in Brockett, 2010) argued that HR leadership is essential for ensuring that all stakeholder groups' interests are met, not alone employees and line managers, but customers, investors and the community. He further proposed that HR professionals, as leaders, need to guarantee their organization's long-term focus by making further investments in developing their workforce's skills, and by creating an adaptive, agile and flexible organizational culture, structure and climate. In line with a "high-commitment" HR model, the author suggested that HR leaders need to intensify and extend their "high-commitment" management styles towards "command and control" approaches (Brockett, 2010). In a similar vein, Roche et al. (2011: 36) outlined that he EC can be proved a good starting point for HR to demonstrate its capacity of creating value and reducing risk, by making sound business decisions through business partnering (Personnel Today, 2008). Cooper (2009) also demonstrated an optimistic attitude for HR towards crisis' incidences, by suggesting that it could be the "making of HR" through promoting leadership and the creation of a strong organizational culture, both essential elements for helping organizations being at the forefront of recovery rather than simply offering a compliant support function. Overall, this strand argues that the crisis offers great opportunities for innovation, creativity and leadership (Roche et al., 2011). Finally, within the third strand of argumentation, the new labour, work and employment relations are viewed as pragmatic, eclectic and incremental in nature, while firms' responses to crisis are seen to be marked by significant continuities with pre-crisis trends, while involving complex and even contradictory sets of measures (Roche \& Teague, 2012: 3). This view involves the use of multiple pay and headcount reductions in sets of measures or retrenchment programs (Roche \& Teague, 2012: 4). For example, firms' responses may result to decreased job security and increased work intensity; however, by suggesting that these measures are aiming at preserving or increasing employees' engagement (Flannery et al., 2005). Obviously, HR is seen to be affected by constant changes, some of them of possibly lasting significance, others probably recurring or transitional (Roche et al, 2011).

\section{Business Life Cycle Stages, Obstacles and Competitive Strategies}

As pointed earlier, Hoy's (2006) model of organizational life cycle includes the stages of birth (start-up), growth, maturity and decline (renewal or death). Within each stage, organizations are likely to face various and diverse obstacles which will affect the HR 


\section{MInstitute ${ }_{\text {Mnk }}^{\text {Macrothink }}$}

strategies organizations adopt in order to overcome these challenges. To that end, organizations' responses, through all aspects of their HR activities, will be different depending on the stage of their business life cycle, along with their HR focus, as summarized by Gao and Alas (2010) and it will further discussed within the following sections.

\begin{tabular}{|c|c|}
\hline Stages & Obstacles \\
\hline $\begin{array}{l}\text { Stage 1. } \\
\text { Start.Up }\end{array}$ & $\begin{array}{l}\text { - Tasks are generally distrobuted in unorganized ways (The working } \\
\text { environment is generally frantic) (Adizes, 1979). } \\
\text { - Informal structure leads to production inefficiency (Greiner, 1998). } \\
\text { - There is heavy workload on founders (Adizes, 1979). } \\
\text { - It struggles for capital and financial aids (Greiner, 1998). }\end{array}$ \\
\hline $\begin{array}{l}\text { Stage } 2 . \\
\text { Groweth }\end{array}$ & $\begin{array}{l}\text { - Despite the fact that creativity and entrepseneurial spint are diminished, } \\
\text { there are still no systemized regulations or procedures (Adizes, 1979). } \\
\text { - It stll struggles for capital or financial supports (Adizes, 1979). } \\
\text { - The ownership is still concentrated on the founder and there is no } \\
\text { helping hand in management department (Adizes, 1979). } \\
\text { - There ase no established long-term goals (Adizes, 1979). } \\
\text { - Company is inexperienced in financial records system (Adizes, 1979). }\end{array}$ \\
\hline $\begin{array}{l}\text { Stage } 3 . \\
\text { Mature }\end{array}$ & $\begin{array}{l}\text { - There is a higher possibility of break-up between partners(Adizes, } \\
\text { 1979), } \\
\text { - Formalized policies are diminishing fast communication (Adizes, 1979; } \\
\text { Greiner, 1998). } \\
\text { - Administrative control is increased on the expense of creativity but the } \\
\text { structure is still ambarvalent (Adizes, 1979, Greiner, 1998). } \\
\text { - Less investment is put on R\&D (Adizes, 1979). } \\
\text { - Rigid structure undermines fast communication (Adizes, 1979). } \\
\text { - Any recognized problems are hidden as the departments have } \\
\text { conflicting interests (Adizes, 1979). } \\
\text { - It is more complicated to control diverse departments (Greiner, 1998), }\end{array}$ \\
\hline $\begin{array}{l}\text { Stage } 4 . \\
\text { Decline } \\
\text { (Re-birth or Death) }\end{array}$ & $\begin{array}{l}\text { - Adaption and flexibility become the key issues for development, but it } \\
\text { requires times and investment (Greiner, 1998). }\end{array}$ \\
\hline
\end{tabular}

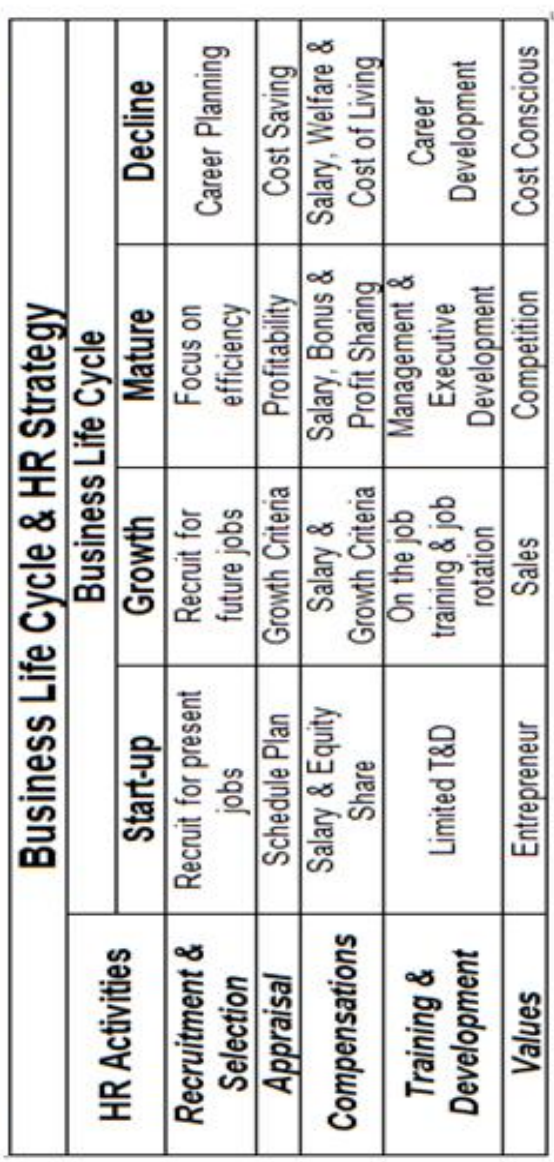

\subsection{Business Life Cycle - "Birth” Stage}

At the "birth" stage, firms try to enter the business world, by identifying the appropriate market segment in order to offer their products/services by following specific (pre-set by competition) price options, promotion and distribution approaches (Allen, 1999). At this stage, organizations usually face tight labour markets and regulations since they are considered as "new entrants" to the market. The recruitment and selection of high-caliber employees is considered crucial at this early growth stage, since firms aim at providing their products/services before their competitors (Marchington \& Wilkinson, 2005; Kochan \& Barocci, 1985). In that event, since there are time constraints, organizations tend to rely on recruiting from the external environment. Most of the time, at this stage of their life cycle, businesses are paying lower priority to HR costs as they want to attract the best candidates. Consequently, that results in the development of high costs in recruiting and selection and moderate costs in training and development (T\&D) as most of them tend to avoid providing training to existing employees (Kochan \& Chalykoff, 1986). A major problem within this 
stage is that organizations have to face a possible lack of expertise from the top management team. Top management, along with HR executives, should prioritize crucial issues related to organization's survival. One of these issues is to attract talented employees who will be committed and fully engaged to the achievement of the organizational objectives; yet, it is difficult to ulcerate capable executives or personnel with extensive experience from competitors (Vaxevanidou \& Reklitis, 2008: 45-47). As organizations are at the early stages of their life, they lack of structured operations and clear definition of roles. Business objectives and goals may be under-defined as firm's top priority is to generate capital. To that end, firms tend to be product inefficient and eventually to present low growth rate (Beverland \& Lockshin, 2001). While being quite flexible at this stage, organizations should highlight the importance of controlling their business costs which may be inhibitive at later stages of their life. In order to overpass these obstacles and to move to another stage of its life cycle, the creation and promotion of a "collaborative" and "motivational" culture is highly required in order to reduce turnover rates, absenteeism and other negative results associated with a de-motivated and non-committed workforce. For that reason, in early growth stages, organizations' top priority is to maintain "employment stabilization" (Kochan \& Chalykoff, 1986). More precisely, in the banking industry, institutions operate in a highly competitive industrial climate, while facing uncertain market conditions and unlimited opportunities as well. To survive and compete, banks need to build strong relationships with their customers throughout each stage of their life cycle. At this stage, banking institutions should be able to understand market's needs in order to build and offer competitive products/services. By identifying the targeted customers, understand their needs and behaviors, they would be able to create strong relationships with them. That will be the initial step for their operations and will help them to further develop their business, and eventually to move to the next stage of their BLC. For that reason, banks ought to be creative, imaginative and innovative despite their start-up organizational weaknesses. Nonetheless to highlight the importance of recruiting and selecting the proper employees, who would perform at outstanding standards so to meet the organizational objectives, and eventually to boost their organization's effectiveness and competitiveness.

\subsection{Business Life Cycle - “Growth” Stage}

Moving up to its next life cycle stage, the "growth" stage is also an important step for the organization. Here, its products/services, after having survived the start-up phase, they start to reach a higher level of demand and the firm starts to generate high levels of sales growth and profits. For that reason, firms are trying to target new customers and new market segments in order to boost their sales, while to build strong customer loyalty as well (Adizes, 2004). Concurrently, at this stage, new competitors may appear by offering premium prices and diversification in order to gain a market share. Therefore, firms have to differentiate themselves by promoting and advertising their offerings in order to maintain their market shares, while trying to build a loyal customer base. Hence, new talented and highly skilled staff is needed (Lawler \& Drexler, 1984). Manpower, at this stage, has to demonstrate that it possesses the knowledge, the will and the skills to cope with the changes and challenges 
occur within the market. At the stage of "birth" and "growth", organizations are likely to be individualized by adapting and implementing innovative HR practices that involve job security, employees' participation in decision making, and HR's involvement in strategy formulation and execution. Eventually, businesses are looking for creative ways to make this happen while still engaging their workforce, reinforcing productive and positive behavior, retaining staff etc. Especially, in regard to employees' participation in decision making process, employees should evince the following characteristics: 1) being creative and innovative, 2) demonstrating a team-work oriented mentality, 3)being long-term focused, 4) being open and adaptive to changes and willing to take risks, 5) being responsible and ready to accept further responsibilities (Drucker, 1993). All these characteristics can be enhanced through extensive $\mathrm{T} \& \mathrm{D}$, coaching and mentoring; all these activities, if well implemented, they would increase employees' motivation, commitment and engagement.

Furthermore, in response to these creative ways, employers are also considering work-life options by offering employees financial management resources (e.g. debt management, budgeting or foreclosure prevention), and counselling services (e.g. an investment with a demonstrable return on investment) as well (Littlecott \& Dunham, 2008). In this stage of the BLC, labor supply is greater, as more and more employees (in all levels) are interested to be hired by organizations that provide job security, satisfactory compensation packages, and they demonstrate a strong brand name and reach high levels of confidence within the market (Vaxevanidou \& Reklitis, 2008: 45-47). However, moving to this stage, the organizational flexibility appeared in the start-up phase starts to diminish as the firm tries to develop its structure so to effectively manage its operations. Furthermore, organizations that have not established long-term objectives tend to "fight" for their survival; contrariwise, those with established goals are liable to better growth rates. However, despite the increased levels of organizational motivation and commitment, and business's will to move forward and maintain growth, it still faces financial problems (Adizes, 1979). Whilst, at this stage, customer relationships have been established through a continuous interaction between customers and organizations, the latter should not rest upon that and stop delivering new and innovative products/services. Especially for banking institutions, they have to continuously highlight the benefits of their offerings, while, concurrently, trying to identify market's future demands. By conducting a careful industry and customer analysis, banks will manage to measure market's satisfaction towards their services, and they will be able to maintain a continuous and successful communication with their clients. Once more, if all that do not occur, it will be difficult for them to move along their life cycle stages. To successfully address all these issues, banking organizations should follow a people-oriented recruiting focus, hiring customer-focused and sale capable employees, identifying their training needs and implementing T\&D activities which will increase their skills and capabilities so to be prepared for moving into the new era after the economy's recovery.

\subsection{Business Life Cycle - "Maturity” Stage}

Within the "maturity" stage, firm's products/services are well established in the market, but sales are growing at a reduced rate, while customers' rate gradually shrinks and profits follow a downward trend. At this stage, organizations engage in internal labor movements to cover 
occasional, seasonal or more permanent needs, while trying to preserve existing jobs. Usually, within this phase of BLC, there is not any new hiring as organizations follow a more modest containment and leverage policy for their workforce (Vaxevanidou \& Reklitis, 2008). Even though labor supply is maintained at high levels, it gradually awakes downward trends (Terzidis \& Tzortzakis, 2004). In this phase, HR worries mainly focus on cost reduction policies (compensation reductions, employment redundancies and lay-offs, reduced expenditures on T\&D etc.). Especially in respect to EC's aftermaths, which resulted in rapid changes within the corporate environments, organizations restructured and downsized their workforce in order to be more cost efficient (McKinley et al, 1998), or placed their employees under short-time contracts (Lallement, 2011). These downsizing and layoff activities resulted in the shifting of accountability for career management activities from employers to employees (Lee et al., 2003). Furthermore, deep economic downsizings generally affect the conduct of employment relations by inclining employers towards more market-responsive postures that may involve downsizing and more flexible employment arrangements, less investment in $T \& D$ and general restructuring activities that may weaken internal labor markets and assured career progression (Roche et al, 2011). Other options employers are considering, in order to deal with the crisis include: reducing the workweek, mandatory holiday shut down, benefit program freezes etc. However, organizations should balance the benefits of cost reduction actions with the overall loss of what is being cut. All these cost reduction decisions will result to short-term positive effects; yet, the longer a crisis remains, the greater the negative long-term effects will be either if they decide to continue their operations at the same stage of their life cycle or to move to another (Milic, 2013: 82). A study conducted by Teague \& Roche (2013: 20) outlined that, during recessionary times, HR practices tend to be implemented accumulatively, and can be described either as technical (payroll cost savings and headcount management) or behavioral (employees' motivation \& commitment, competency development, training etc.) in character. In general, at this stage, organizations try to restructure and reorganize their operations by seeking lower labor cost environments. However, there are organizations that still try to recruit and maintain a competitive workforce even though its loyalty may not be considered notable important at this stage (Lynch \& Orne, 1985). Although firms reach the peak of their performance at this stage, and eventually are less likely to fail, they are still trying to maximize their profits through the existing products/services. Meanwhile, they are also targeting at increasing their return on investment from investments made within the previous stages of their life cycle. However, new and smaller firms tend to demonstrate the highest growth rates here (Phelps et al., 2007: 3). Instead of being more proactive in their roles, organizational functions tend to be reactive by shifting back to their traditional HR policies in order to get maximum effectiveness; eventually, they put less emphasis on T\&D, research and development and effective organizational communication (Kochan \& Chalykoff, 1986).

The main problem of a mature organization is its resistance to change and innovate. Furthermore, as business structure becomes more hierarchical, employees' interaction and participation starts to abate (Adizes, 1979). Nonetheless, this is not a common reaction. Dynamic organizations continuously seek for innovative ways to manage their operations by holding to their values and absorbing the transition costs until a new business reality to 


\section{Ml Macrothink}

emerge (Kochan \& Chalykoff, 1986). Contrariwise to the previous stages, organizations, within the mature stage, are facing high levels of industrial competition, unless there are extensive market entry barriers. Furthermore, in general, and in regard with the current EC, firms operating within the "growth" and "maturity" life stages tend to be more resilient to crisis, and eventually more capable of managing its negative effects or exploiting the positive ones. Gao \& Alas (2010) research on Chinese organizations demonstrated that the majority of the investigated firms were at the stage of maturity within their BLC during the global financial crisis, while the EC has been identified as the most affective type of crisis within each stage of the organizational life-cycle. In this regard, in exchange for overcoming the negative effects of the crisis, firms either move to the next stage of "decline" within which their "renewal" or "death" is uncertain, or they are trying to address the problems associated with crisis and continue to operate at the same stage until they will eventually be called to move to another stage as part of the overall forces (internal \& external) which impose this shift. Banks at the mature stage of their life are trying to differentiate by offering quality and distinctive services/products by adapting quality enhancement and innovation strategies (Fulkerson, 1997). They are generating "tailor-made" services and products that are customized to the specific needs of their customers at outstanding service delivery standards (Zineldin, 1996). Here, the concept of mass customization derives and premises the occupation of a large market share and customers' base, and banks' ability to offer unique products/services that match the unique needs of each customer (Kardaras \& Papathanasiou, 2001). Further external forces (globalization, technological advances, restructurings etc.) provide opportunities to banks if they want to differentiate and innovate (e.g. e-banking), while for how long mature banks will be able to maintain their success highly depends on their ability to protect their existing market segments or, whenever possible, to increase them.

\subsection{Business Life Cycle - "Decline" (Renewal or Death) Stage}

Finally, in the "decline" stage of their BLC, organizations are facing two options: either to "re-birth" and start a new life cycle from scratch, or to "die" by terminating their operations. At this stage, sales decline at an extraordinary rate, and the potential for recovery through creating and promoting new products/services is very difficult, nor impossible. Surviving firms try to build new strategies in order to maintain their operations, to assure their market shares, and to create profitability. Similarly as within the mature stage, here companies usually proceed to lay-offs and staff redundancies. Concurrently, they are trying to sustain the most efficient and productive employees, keeping them satisfied and motivated either by repositioning them in areas where they can perform better and more efficiently, or by upgrading them to higher positions of responsibility. It is worth noting that capable staff and executives, who are employed by companies that are in decline, they seek transferring to other firms within the industry which they are at the developmental stage and they are offering better pay, career development opportunities and better working conditions (Terzidis $\&$ Tzortzakis, 2004). The main concern of the business should be the effective management and retention of the talented employees, since labour supply of senior and capable executives is very low in the market (Vaxevanidou \& Reklitis, 2008). Within this stage, organizations are 
facing similar obstacles as in the mature stage, however, the option of their "renewal" or "death" forces them to consider re-investments in their business operations, primary in order to avoid "death", and consequently to enter a new business life cycle. Either for their survival or re-birth, organizations would be better to implement a quality enhancement strategy if they seek to retain or regain market share and to maintain their customers' satisfaction and loyalty. As a result of the recent economic crisis, many organizations moved to this stage and faced with the two options provided. Just as it is those companies that prepared for the downturn (death) that will come through, there are also those companies that anticipate the upturn (renewal), and they will be those that are going to be most quickly profit and prosper (Brown \& Reilly, 2009). More precisely in the banking industry, following the rapid expansion of private banking in 1991-1997, and the rapid growth of the banking sector within the last decade, Greek banks balance between the mature and decline stage of their BLC. Being 16 in numbers before the EC, its aftermaths resulted in many restructures, mergers and acquisitions that eventually shrank the banking industry into four to five major groups. That was a major challenge for HR to cope with as the industry performs in a deregulated business environment with limited control applied by the government through the Bank of Greece (Kardaras \& Papathanasiou, 2001: 293). All these acquisitions and mergers mark the "death" of an institution, and its "re-birth" under the umbrella of a new - larger banking corporation.

However, where HR managers were proactive in positioning their HR practices, systems and policies to support business revival over the medium or long-term, they managed to be ahead of the crisis (Roche et al., 2011). Therefore, HR professionals need to do a thorough analysis of the responses to the crisis and recovery plans adopted by different companies for successful survival, as the crisis will not last forever. By the time the economy will start to turnaround, a recovery plan will be required in order to support organizational efforts for post-recession revival. Organizations should not revert back to their old practices, but they will need to develop innovative and proactive HR practices, focusing on creating opportunities for their HR team to demonstrate its value, and for organizations to start a new successful business life cycle. In that event, HR executives should grasp these opportunities in order to reshape and restructure their workforce and to initiate the bounce back process of their company for post-crisis success.

\section{Conclusion}

Today's turbulent business environment calls for organizations to be carefully advanced over the stages of their business life cycle, by demonstrating willingness of promoting creatitiveness, innovativeness, organizational change, cooperation, and well-coordinated restructing implementations when needed. The different HR practices that firms will implement at each stage of their BLC, in accordance with their competitive strategy, will affect their organization's effectiveness. Consequently, the execution of a specific competitive strategy, followed by the appropriate HR practices, are highly dependent to life cycle of the business. The success of a firm will be heavily influenced by the successful management of its processes thoughout every stage of its life cycle. Having the right employees at the right place and at the right time will enable organizational growth and economic viability, while it 
will assist top management and HR team to take the proper decisions throughout the BLC and eventually to help the organization prosper. It is essential to keep in mind that every time the organization moves to a new stage of its life cycle, changes to its culture and work environment may occur. Employees should be continuously informed and engaged during these organizational shifts. The effective organizational life cycle management presupposes a continuous alter of business' focus according to the firm's life stage. Identifying and understanding the life stage in which an organization operates is essential for both the management and future plans. Finally, by acknowledging the obstacles related with each phase, organizations can identify their problems and eventually to re-shape their corporate and HR strategies.

The unpredictable nature of crisis calls for organizations to develop flexible, adaptive and agile structures and systems so to effectively respond to a variety of contingent situations within business environments. The longer the crisis takes in unfolding, the greater the number of contingencies in the business environment it produces and the greater or less its impact on business life cycle will be. The challenge for HR is to deal in a professional and sensitive manner with downsizing; to innovate in work organization and processes; to ensure that talent and skills for the future are retained; and to plot the course for the time that will come after the crisis. All that demand having the right policies and practices for the new slimmed down and much-changed world or for the new life cycle stage that the organization may shift. Paths that HR needs to follow in order to improve its effectiveness within organizations suggest a "long term" commitment; maintain employees' engagement; strengthen line management capability; support employees' health and well-being; develop a strategy for redundancy; find ways to minimize retrenchments if staffing reductions are unavoidable; consult with the workforce and their representatives; establish fair and objective selection criteria for redundancy; provide advice and support for people losing their jobs; plan for the future, especially by reallocating jobs and responsibilities; provide training for new jobs; and communicate with employees at all stages (CIPD, 2008). Either surviving a crisis or shifting to a new stage of their life cycle, organizations and their HR professionals should consider that as opportunity rather than as threat. All in all, all that presupposes the strategic positioning of HR within the organizational context, by accepting its activities and deliverables of equal strategic importance as the other business actions.

\section{References}

Adizes, I. (1979). Organizational passages: diagnosing and treating lifecycle problems of organizations. Organizational Dynamics, Vol.8, Issue 1, pp.3-25.

Adizes, I. (2004). Managing Corporate Lifecycles: How to get to and stay at the top. An Updated and Expanded Look at the Classic Work Corporate Lifecycles, Published by: The Adizes Institute Publishing.

Allen, K.R. (1999). Growing and Managing an Entrepreneurial Business. Boston: Houghton Mifflin Company.

Baird, L. and Meshoulam, I. (1992). Getting pay-off from investment in human resource management. Business Horizons, Vol.35, Issue 1, pp.68-75. 
Beverland, M. and Lockshin, L.S. (2001). Organizational life cycles in small New Zealand wineries. Journal of Small Business Management, Vol.39, Issue 4, pp.354-362.

Brockett, J. (2010). See HR as a Professional Services Firm, Says Ulrich. People Management, 25 March, p.11.

Brown, D. and Reilly, P. (2009). HR in Recession: what are the prospects and priorities for HR management in 2009?", Opinion Paper OP15, Institute for Employment Studies; March 2009, pp.1-6, http://www.employment-studies.co.uk/pdflibrary/op15.pdf

Carter, S. and Jones-Evans, D. (2012), “Enterprise and small business: Principles, Practice and Policy", $3^{\text {rd }}$ Edition, Pearson Education Limited, pp.405-410.

Chartered Institute of Personnel and Development (CIPD). (2008). How to Manage Your Workforce in a Recession. A Joint ACAS and CIPD Guidance Note, London: CIPD, pp.1-16, http://www.acas.org.uk/CHttpHandler.ashx?id=1113\&p=0

Conner, I. and Ulrich, D. (1996). Human resource roles: Creating value, not rhetoric. Human Resource Planning, Vol.19, No.3, pp.38-49.

Cooper, C. (2009). The Recession could be the Making of HR. HRM Magazine, 3 February 2009, http://www.hrmagazine.co.uk/hro/features/1016812/this-recession-hr

Drucker, P.F. (1993). Innovation and Entrepreneurship: Practice and Principles. New York: Harper Business: HarperCollins Publishers, pp.21-24.

Flannery, J., Stasi, K., Nolan, M., Davies, S., McKee, K. and Warnes, T. (2005). Experiencing training: the need for a detailed investigation. Working with Older People, Vol.9, Issue 1, pp.13-16.

Fulkerson, B. (1997). A response to dynamic change in the market place. Decision Support Systems, Vol.21, No.3, pp.199-214.

Gao, J. and Alas, R. (2010). The Impact of Crisis on enterprise Life-Cycle. Management in firms and organizations, Problems and Perspectives in Management, Vol.8, Issue 2, pp.9-20.

Hoy, F. (2006). The complicating factor of life-cycles in corporate venturing. Entrepreneurship: Theory and Practice, Vol.30, Issue 6, pp.831-836.

Jackson, S.E. and Schuler, R.S. (1995). Understanding Human Resource Management in the context of Organizations and their Environments. Annual Review of Psychology, Vol.46, pp.237-264.

Kardaras, D. and Papathanasiou, E. (2001). Electronic commerce opportunities for improving corporate customer support in banking in Greece. International Journal of Bank Marketing, Vol.19, Issue 7, pp.292-298.

Kochan, T.A. and Barocci, T.A. (1985). Human Resource Management and Industrial Relations: Texts, Readings, and Cases. Little, Brown Publisher, Boston. 
Kochan, T.A. and Chalykoff, J. (1986). Human Resource Management and Business Life Cycles: Some Preliminary Propositions. Working Papers, Massachusetts Institute of Technology (MIT), Sloan School of Management, No.1821-1886, Available at: http://dspace.mit.edu/handle/1721.1/2153

Kozlowski, S.W.J., Chao, G.T., smith, E.M. and Hedlund, J. (1993). Organizational Downsizing: Strategies, Interventions and Research Implications. In Cooper, C.L. and Robertson, I.T. (Eds.), International Review of Industrial Organizational Psychology, Vol.8, New York: Wiley, pp.263-332.

Lallement, M. (2011). Europe and the Economic Crisis: Forms of Labor Market Adjustment and Varieties of Capitalism. Work, Employment and Society, Vol.25, No.4, pp.627-641.

Lawler, E.E. and Drexler, J.A. (1984). The Corporate Entrepreneur. Working Paper, Centre for Effective Organizations, University of Southern California, May 1984, pp.1-13.

Lee, S-H., Phan, H.P. and Tan, W.Y.G. (2003). Impact of the Asian economic crisis on training intentions and outcomes. Human Resource Management Review, Vol.13, Issue 3, pp.467-486.

Lippitt, G.L. and Schmidt, W.A. (1967). Crises in a developing organization. Harvard Business Review, Vol.45 (6), pp.102-112.

Littlecott, L. and Dunham, P. (2008). The Impact of the Economic Crisis on our Organization's Human Resources. Strategic Human Resources Inc.

Lynch, J. and Orne, D. (1985). Managing in the belly of the cow. Management Review, June 1985, pp.4646-4648.

Marchington, M. and Wilkinson, A. (2005). Human Resource Management at Work: People Management and Development. $3^{\text {rd }}$ Edition, Published by the Chartered Institute of Personnel and Development (CIPD), pp.100-109.

McKinley, W., Mone, M.A. and Barker, V.L. (1998). Some ideological foundations of organizational downsizing. Journal of Management Inquiry, Vol.7, No.3, pp.198-212.

Metzger, O.R. (1989). Organizational Life Cycles in Banking. Group and Organization Management, Vol.14, No.4, pp.389-398.

Milic, T. (2013). Innovation Management in Times of Economic Crisis. Management Journal for Theory and Practice Management, University of Belgrade, http://www.management.fon.rs/management/e_management_66_english_07.pdf

Milliman, J., Von Glinow, M.A. and Nathan, M. (1991). Organizational life cycles and strategic international HRM in multinational companies: Implications for congruency theory. Academy of Management Review, Vol.16, No.2, pp.318-339.

Personnel Today, (2008). Ulrich Calls on HR to Use Recession to Scrap Jobs. Personnel Today, 9 December 2008. 
Phelps, R., Adams, R. and Bessant, J. (2007). Life Cycles of growing organizations: A review with implications for knowledge and learning. International Journal of Management Review, Vol.9, No.1, pp.1-30.

Phillips, L. (2008). Firms Plan to Hire More HR Staff despite UK Job Cuts. People Management, Vol.14, Issue 4, p.9.

Pitcher, G., (2008). The Global Economic Crisis Will Decimate HR Departments in 2009. Personnel Today, 8 December.

Porter, M. (1985). Competitive Advantage: Creating and Sustaining Superior Performance. New York: Free Press.

Roche, K.W. and Teague, P. (2012). Do Recessions Transform Work and Employment? Evidence from Ireland. British Journal of Industrial Relations, early View (Online Version of Record published before inclusion in an issue), Blackwell Publishing Ltd/London School of Economics 2012, November 2012, pp.1-25, Article available at: http://onlinelibrary.wiley.com/doi/10.1111/bjir.12006/pdf

Roche, K.W., Teague, P., Coughlan A. and Fahy, M. (2011). Human Resources in the Recession: Managing and Representing People at Work in Ireland. Final Report Presented to the Labor Relations Commission January 2011, Executive summary, pp.1-48, Available at: http://www.Irc.ie/documents/symposium11/Exec-Summary-Human-Resources-in-the-Recessi on.pdf

Schein, E.H. (2010). Organizational Culture and Leadership. $4^{\text {th }}$ Edition, San Francisco: Jossey-Bass Publication, August 2010.

Smith, K.G., Michell, T.R. and Summer, C.E. (1985). Top management priorities in different stages of organizational life cycle. The Academy of Management Journal, Vol.28, No.4, pp.799-820.

Susaeta, L., Suarez, E. and Pin, J.R. (2013). Economic crisis and communication: The role of the HR manager. Business Systems Review, Vol.2, Issue 2, pp.278-296.

Teague, P. and Roche K.W. (2013). Recessionary bundles: HR practices in the Irish economic crisis. Human Resource Management Journal, Early view, Online version before inclusion in an issue, Article is available at; http://onlinelibrary.wiley.com/doi/10.1111/1748-8583.12019/pdf

Terzidis, K. and Tzortzakis, K. (2004). Human Resource Management - Personnel Management. Athens, Rosili Publishing.

Vaxevanidou, M. and Reklitis, P. (2008). Human Resource Management. Athens, Metehmio Publications, pp.45-47.

Zineldin, M. (1996). Bank-corporate client 'partnership' relationship: benefits and life cycle. International Journal of Bank Marketing, Vol.14, No.3, pp.14-22. 